\title{
A comprehensive FFQ developed for use in New Zealand adults: reliability and validity for nutrient intakes
}

\author{
Cecilia HY Sam, Sheila Skeaff and Paula ML Skidmore* \\ Department of Human Nutrition, University of Otago, PO Box 56, Dunedin, New Zealand
}

Submifted 2 August 2012: Final revision received 18 September 2012: Accepted 21 September 2012: First published online 3 December 2012

\begin{abstract}
Objective: To evaluate the reliability and relative validity of a semi-quantitative FFQ for assessing the habitual intake of multiple nutrients in New Zealand (NZ) adults over the past 12 months.

Design: A 154-item FFQ was developed. After initial pre-testing, reliability was assessed using intra-class correlations. Relative validity was assessed by comparing nutrient intakes derived from the FFQ $v$. those from an $8 \mathrm{~d}$ diet record (8dWDR) collected over 12 months and selected blood biomarkers, using Spearman correlations. Supplementary cross-classification and Bland-Altman analyses were performed to assess validity of the FFQ $v$. the 8dWDR.

Setting: Dunedin, NZ.

Subjects: One hundred and thirty-two males and females aged 30-59 years who completed all FFQ and 8dWDR and provided a blood sample.

Results: Reliability coefficients ranged from 0.47 for Ca to 0.83 for alcohol, with most values falling between $0 \cdot 60$ and $0 \cdot 80$. The highest validity coefficients for energy-adjusted data were observed for alcohol $(0 \cdot 74)$, cholesterol $(0 \cdot 65)$ and $\beta$-carotene $(0 \cdot 58)$, and the lowest for $\mathrm{Zn}(0 \cdot 24)$ and $\mathrm{Ca}(0 \cdot 28)$. For all energyadjusted nutrients mean percentage correct classification was $77 \cdot 9 \%$ and gross misclassification was $4 \cdot 5 \%$. Results of Bland-Altman analyses showed wide limits of agreement for all micronutrients but high agreement was observed for most macronutrients (99\% for protein, $103 \%$ for total fat). When compared with biomarkers, energy-adjusted coefficients were 0.34 for $\beta$-carotene and 0.33 for vitamin C.

Conclusions: The FFQ provides highly repeatable measurements and good validity in ranking individuals' intake, suggesting that it will be a useful tool to assess nutrient intake of NZ adults in future research.
\end{abstract}

Diet is one of the major modifiable risk factors for many chronic conditions, such as CVD and type 2 diabetes ${ }^{(1)}$. Investigating the relationship between diet and disease is the focus of many epidemiological studies worldwide ${ }^{(2,3)}$. There are many methods to measure food and nutrient intakes including $24 \mathrm{~h}$ recalls, weighed or estimated food records and $\mathrm{FFQ}^{(4,5)}$. FFQ are a widely used tool in large epidemiological studies, due to their low cost and the ease of administration compared with other more intensive dietary assessment methods ${ }^{(4-6)}$. As with any method of dietary assessment, there are also limitations associated with $\mathrm{FFQ}^{(4-7)}$. Therefore, it is vital to use an FFQ in a target population of a specific age range, physiological status and cultural background for which it has been designed $^{(7)}$. For example, an FFQ designed for use in adults from the UK or the USA may not be suitable for use in the New Zealand (NZ) population, due to differences in food availability, food choice and subsequent intake between populations ${ }^{(7,8)}$. When an FFQ is designed for use in a particular population, or if a modified version of a previously available questionnaire is developed for use in another population, it is crucial that the reliability and validity of the tool are assessed in the target population prior to its use $\mathrm{e}^{(7,8)}$. It is also important to ensure that a validated FFQ is up to date, as using an FFQ that was developed many years ago may not accurately reflect current food availability or consumption patterns ${ }^{(5,8)}$.

In NZ, relative validity has been investigated for only four FFQ designed for assessing multi-nutrient intakes in free-living adults ${ }^{(9-13)}$. Of these FFQ, both validity and reliability have been assessed only once ${ }^{(12)}$, and all FFQ were validated more than 10 years ago and have not been updated for current use. Therefore, the aim of the present study was to develop a multi-nutrient FFQ to rank participants by nutrient intake, and to investigate its reliability and relative validity. This FFQ is intended to be used in large cohort studies of NZ adults to investigate relationships between nutrient intake and chronic disease. 


\section{Methods}

\section{Participants and study design}

A convenience sample of 151 participants aged between 30 and 59 years was recruited from the general population in Dunedin, NZ between September 2009 and May 2010, in order to recruit fifty participants (twenty-five males, twenty-five females) in each of the following age bands: 30-39 years, 40-49 years and 50-59 years.

Each participant attended four clinic visits over 12 months. During this 12-month period, participants would complete the FFQ on two occasions nine months apart, in order to assess repeatability of the FFQ. Participants were randomised so that half of them completed the FFQ at month 0 and month 9, and half at month 3 and month 12 . At the first clinic visit (month 0), the purpose of the study and the procedures involved were explained to all participants and informed consent was given before participation. Height and weight were measured in duplicate, according to a standard operating procedure. Participants filled out a demographics questionnaire. Half of the participants completed the FFQ at month 0 as allocated. Participants were then given verbal instructions by a trained nutritionist on to how to complete weighed food records. Each participant was provided with a diet record package containing a $2 \mathrm{~d}$ weighed diet record (2dWDR) with further written instructions on weighing and recording foods, a set of scales and a pre-paid envelope for return of records; 2dWDR were to be completed within two weeks of the first clinic visit. The second clinic visit took place at month 3, where the remaining half of participants completed the FFQ. The rest of the visit followed the same protocol as month 0 and participants were provided with a second $2 \mathrm{dWDR}$. At month 6 , the third 2dWDR was sent to participants by post along with a pre-paid envelope. Participants attended the clinic again at months 9 and 12. All participants were given another 2dWDR and pre-paid envelope at month 9. Those participants who completed the FFQ at month 0 filled in the FFQ for a second time at the month 9 visit and those who completed it at month 3 did so again at month 12 . At month 9, two $10 \mathrm{ml}$ fasting blood samples were also obtained from each participant for analyses of selected nutrient biomarkers. The study was approved by the University of Otago Human Ethics Committee.

\section{Development and administration of the FFQ}

The FFQ was developed by modifying a 147-item, semi-quantitative FFQ used in the UK-EPIC (European Prospective Investigation into Cancer and Nutrition) project. Changes to the FFQ were made to ensure that all foods listed made a substantial contribution to nutrient intake and were commonly consumed by NZ adults. Commonly consumed foods were identified using data from the 1997 NZ National Nutrition Survey ${ }^{(14)}$, the most recent nationally representative data set available at the time. Two inspection tours of Dunedin supermarkets were carried out to identify other relevant foods for inclusion. Examples of changes made to the UK FFQ included removal of items not generally available in NZ (e.g. coffee whitener), addition of foods that were not included in the original EPIC FFQ but are commonly consumed in NZ (e.g. pumpkin and kumara), and naming changes to reflect the local context (e.g. 'sweet peppers' was changed to 'capsicum').

The modified FFQ was pre-tested in a total of twentyone adults aged 30-59 years using focus group interviews and then modified according to feedback received. The finalised semi-quantitative FFQ captures the habitual intake of 154 food items, using seven frequency options ranging from 'never or less than once per month' to 'two or more every day'. Most questions requested information on the average consumption of foods over the past 12 months, while the intake of seasonal fruits was expressed as 'average intake when in season'. Supplementary multiple-choice questions were included to identify supplement use and cooking methods such as trimming of fat. A nutrient line for each food item, weighted by the proportion of New Zealanders who consume each food in a particular food item, was determined using data on food consumption patterns from the NZ 2008/09 Adult Nutrition Survey (ANS) ${ }^{(15)}$. For example, the nutrient lines for the FFQ item 'beer' were weighted to $70 \%$ of the nutrient data for 'standard draught and lager' and 30\% 'strong ale' as the reported frequency of consumption of the former was $2 \cdot 33$ times that of the latter in ANS participants.

\section{Validation reference - weighed diet record}

Power calculations indicated that eight recording days were required to capture the habitual dietary intake of participants and to provide intra-class correlation coefficients (ICC) of at least 0.95 for all nutrients, including those with high day-to-day variation in intake (e.g. vitamin C and Se). The present study used weighed diet records, as these have been acknowledged as the most appropriate validation reference for FFQ ${ }^{(5,8)}$. Each participant completed four $2 \mathrm{dWDR}$ for a total of $8 \mathrm{~d}$ of records (8dWDR). Each 2dWDR consisted of two nonconsecutive day blocks (one block per season over 12 months). Participants were randomised so that equal numbers of participants started recording on each of the seven days in a week, with the remaining days of a week following a standard pattern. Participants who had not returned their 2dWDR within two weeks were followed up by email or telephone. All returned 2dWDR were checked for completion by trained nutritionists and a follow-up contact was made to gather more detailed information if needed. Nutrient intake was analysed using the NZ FOODfiles based Diet Cruncher software version 1.6.0 (Way Down South Software, Dunedin, New Zealand). Daily nutrient intake was computed to provide a ratio of $5: 2$ for weekdays to weekend days. 


\section{Validation reference - blood biomarkers}

Blood concentrations of ascorbic acid, $\beta$-carotene and $\alpha$-tocopherol were used as validation references for the respective dietary intakes of vitamin $C, \beta$-carotene and vitamin E, determined from the FFQ and the 8dWDR. Two $10 \mathrm{ml}$ fasting blood samples were obtained from each participant at month 9. Blood samples were processed within $2 \mathrm{~h}$ of collection to minimise the degradation of ascorbic acid. Plasma for ascorbic acid determination and serum for $\beta$-carotene and $\alpha$-tocopherol were obtained after centrifugation at $1500 \mathrm{~g}$ for $15 \mathrm{~min}$ at $4^{\circ} \mathrm{C}$. Plasma and serum samples were stored at $-80^{\circ} \mathrm{C}$ for up to 1 year before analysis. Plasma ascorbic acid concentration was determined using a fluorometric assay ${ }^{(16)}$. This method has an intra-assay $\mathrm{CV}$ at 2,4 and $5 \mu \mathrm{g}$ ascorbic acid/ml of $6.7 \%$, $3 \cdot 2 \%$ and $4 \cdot 0 \%$, respectively. The inter-assay $\mathrm{CV}$ was $4 \cdot 7 \%$. The concentrations of serum $\beta$-carotene and serum $\alpha$-tocopherol were determined concurrently using a liquidchromatographic assay adapted from the method of Thurnham et $a l^{(17)}$. During analyses all samples and standard solutions were handled under natural lighting. A pooled serum sample was run after every ten samples and the intra-assay CV determined daily from the average mean value of each analyte. This method has a mean intra-assay CV of $10.4 \%$ for $\beta$-carotene and $1.7 \%$ for $\alpha$-tocopherol. The inter-assay CV was $9 \cdot 1 \%$ for $\beta$-carotene and $3.5 \%$ for $\alpha$-tocopherol.

\section{Statistical analyses}

All analyses were performed using the statistical software package Stata $11 \cdot 0$. Reliability between the first FFQ administration (FFQtime1) and the second administration (FFQtime2) was assessed using ICC. Relative validity of FFQtime2 $v$. the 8dWDR and blood biomarkers was assessed using Spearman correlation coefficients (SCC). As the purpose of the FFQ is to rank individuals, crossclassification of results between FFQtime2 and the 8dWDR was undertaken. Agreement for cross-classification was presented as the percentage of participants classified into the same and adjacent quartiles, and the percentage grossly misclassified into extreme quartiles. In analyses using SCC and cross-classification, energy adjustment was undertaken using the residual method ${ }^{(18)}$. Supplementary Bland-Altman analyses ${ }^{(19)}$ were performed to assess the strength of agreement between FFQtime2 and the 8dWDR in measuring absolute nutrient intakes. Natural logarithmic transformations were performed on the original scale of the FFQ and 8dWDR data to improve normality ${ }^{(19)}$. Mean differences and limits of agreement (LOA) were back-transformed and expressed as percentages. Thus, a mean percentage agreement of 100 with $95 \%$ confidence intervals including 100 indicates a perfect agreement in assessing absolute mean intake at a population level. The width of the LOA represents the range in which $95 \%$ of the differences between the two methods are expected to fall.

\section{Results}

A total of 132 participants (87\% of those enrolled at baseline) completed the fasting blood test, the 8dWDR and both administrations of the FFQ. No missing data were found, and thus data from all 132 participants were included in the current analysis. The mean age of participants was 44 years, $49 \%$ were male and $81 \%$ were of NZ European origin. Table 1 shows mean energy and nutrient intakes from the 8dWDR and both FFQ administrations. Nutrient intakes obtained from the $8 \mathrm{dWDR}$ were comparable to $24 \mathrm{~h}$ recall data from the NZ 2008/09 $\mathrm{ANS}^{(15)}$. Mean energy intake from the 8dWDR was $9 \cdot 2 \mathrm{MJ} / \mathrm{d}$, which was close to $9 \cdot 0 \mathrm{MJ} / \mathrm{d}$ reported by ANS participants of a similar age ${ }^{(15)}$.

Using ICC, the reliability coefficients for the FFQ administrations spaced 9 months apart ranged from 0.47 for Ca to 0.83 for alcohol, as presented in Table 2 . The majority of ICC were between 0.60 and 0.82 , indicating good to excellent reliability. Table 2 also shows the relative validity of FFQtime $2 v$. the 8dWDR for crude and energy-adjusted nutrient intakes. Energy adjustment generally led to higher correlation coefficients. After energy adjustment, the lowest SCC were observed for Zn $(0 \cdot 24)$, Ca $(0 \cdot 28)$ and vitamin E $(0 \cdot 24)$, whereas the highest SCC were found for alcohol $(0.74)$, cholesterol $(0.65), \beta$-carotene $(0.58)$, carbohydrate $(0 \cdot 56)$ and vitamin $\mathrm{C}(0 \cdot 56)$.

Table 3 shows the agreement in cross-classification between FFQtime2 and the 8dWDR in ranking individuals according to their nutrient intakes. The mean proportion of participants correctly classified to within one quartile for all nutrients was $\mathbf{7 5 \cdot 3} \%$, which increased to $77 \cdot 9 \%$ after energy adjustment. High percentages of correct classification were observed for energy-adjusted intakes of alcohol (91.3\%), cholesterol (84.8\%), carbohydrate $(82 \cdot 6 \%)$, vitamin C (82.6\%) and vitamin E (82.6\%). For all energy-adjusted data, a mean of $4.5 \%$ of participants were misclassified into extreme quartiles.

Strength of agreement between FFQtime2 and the 8dWDR is shown in Table 4. Almost perfect mean percentage agreement (i.e. close to 100 with $95 \%$ confidence intervals including 100) was observed for energy and most macronutrients both before and after energy adjustment. After energy adjustment, no substantial differences in mean agreement were observed, but the range of LOA was narrower for all nutrients. For most macronutrients the FFQ estimates fell between half and two times the 8dWDR estimates, indicating good agreement between methods. Compared with macronutrients, the range of energy-adjusted LOA for micronutrients was generally wider. Figure 1 shows a Bland-Altman plot for energy-adjusted carbohydrate, where the mean percentage agreement between FFQtime2 and the 8dWDR was 103\%.

Mean concentration of blood biomarkers was 68.7 (SD 22.0) $\mu \mathrm{mol} / 1$ for plasma ascorbic acid, 0.59 (SD 0.44) $\mu \mathrm{mol} / 1$ for serum $\beta$-carotene and 26.9 (SD 7.95) $\mu \mathrm{mol} / \mathrm{l}$ for serum 
Table 1 Mean (and standard deviation) daily intakes of energy and selected nutrients among study participants (males and females aged 30-59 years ( $n$ 132), Dunedin, New Zealand, 2009-2010)* and the 2008/09 Adult Nutrition Survey (ANS) +

\begin{tabular}{|c|c|c|c|c|c|c|c|}
\hline \multirow[b]{2}{*}{ Nutrient } & \multicolumn{2}{|c|}{ 8dWDR } & \multicolumn{2}{|c|}{ FFQtime1 } & \multicolumn{2}{|c|}{ FFQtime2 } & \multirow{2}{*}{$\begin{array}{c}\text { ANS } \\
\text { Mean }\end{array}$} \\
\hline & Mean & SD & Mean & SD & Mean & SD & \\
\hline Energy (MJ) & $9 \cdot 2$ & $2 \cdot 2$ & $9 \cdot 8$ & $3 \cdot 0$ & $9 \cdot 5$ & $3 \cdot 0$ & $9 \cdot 0$ \\
\hline Protein $(\mathrm{g})$ & $90 \cdot 1$ & $23 \cdot 6$ & $94 \cdot 7$ & $28 \cdot 2$ & $90 \cdot 8$ & $28 \cdot 7$ & $88 \cdot 8$ \\
\hline Total fat $(\mathrm{g})$ & $78 \cdot 1$ & $25 \cdot 7$ & $86 \cdot 4$ & $30 \cdot 2$ & $81 \cdot 0$ & $27 \cdot 7$ & $82 \cdot 5$ \\
\hline SFA (g) & $29 \cdot 6$ & $12 \cdot 2$ & 33.9 & $13 \cdot 6$ & $31 \cdot 8$ & $11 \cdot 9$ & $32 \cdot 0$ \\
\hline MUFA (g) & $27 \cdot 4$ & $9 \cdot 6$ & $30 \cdot 6$ & $10 \cdot 9$ & $28 \cdot 2$ & $10 \cdot 0$ & $30 \cdot 3$ \\
\hline PUFA (g) & $13 \cdot 0$ & $6 \cdot 0$ & $12 \cdot 8$ & $4 \cdot 3$ & $12 \cdot 3$ & $4 \cdot 4$ & $12 \cdot 0$ \\
\hline Cholesterol (mg) & $267 \cdot 1$ & $139 \cdot 2$ & $269 \cdot 9$ & $128 \cdot 5$ & $256 \cdot 5$ & $127 \cdot 7$ & $283 \cdot 0$ \\
\hline Carbohydrate (g) & $268 \cdot 0$ & $75 \cdot 7$ & $280 \cdot 4$ & $91 \cdot 5$ & $281 \cdot 7$ & $102 \cdot 5$ & $241 \cdot 0$ \\
\hline Sucrose (g) & $46 \cdot 0$ & $19 \cdot 5$ & $59 \cdot 9$ & $27 \cdot 4$ & $58 \cdot 8$ & $29 \cdot 1$ & $49 \cdot 8$ \\
\hline Fructose (g) & $26 \cdot 0$ & $11 \cdot 0$ & $35 \cdot 9$ & $13 \cdot 3$ & $36 \cdot 1$ & $17 \cdot 5$ & $20 \cdot 3$ \\
\hline Fibre (g) & $27 \cdot 7$ & $8 \cdot 8$ & $35 \cdot 7$ & $11 \cdot 3$ & $35 \cdot 5$ & $13 \cdot 4$ & $22 \cdot 1$ \\
\hline Alcohol (g) & $11 \cdot 0$ & $17 \cdot 5$ & $10 \cdot 8$ & $11 \cdot 0$ & $10 \cdot 4$ & $11 \cdot 5$ & $15 \cdot 0$ \\
\hline Total vitamin A $(\mu \mathrm{g})$ & $1063 \cdot 5$ & $775 \cdot 6$ & $1688 \cdot 3$ & $966 \cdot 4$ & $1526 \cdot 7$ & $973 \cdot 1$ & $935 \cdot 0$ \\
\hline$\beta$-Carotene $(\mu \mathrm{g})$ & $4086 \cdot 9$ & $2580 \cdot 4$ & $6891 \cdot 1$ & $3503 \cdot 9$ & $6522 \cdot 0$ & $3741 \cdot 6$ & $2960 \cdot 0$ \\
\hline Thiamin (mg) & $1 \cdot 9$ & $1 \cdot 0$ & $2 \cdot 9$ & $2 \cdot 0$ & $3 \cdot 1$ & $2 \cdot 3$ & $1 \cdot 5$ \\
\hline Riboflavin (mg) & $2 \cdot 1$ & $0 \cdot 7$ & $2 \cdot 9$ & $1 \cdot 6$ & $3 \cdot 0$ & $1 \cdot 8$ & $2 \cdot 0$ \\
\hline Niacin equivalents (mg) & $37 \cdot 9$ & $10 \cdot 6$ & $45 \cdot 0$ & $15 \cdot 0$ & $44 \cdot 1$ & $16 \cdot 4$ & $36 \cdot 7$ \\
\hline Vitamin $B_{6}(\mathrm{mg})$ & $2 \cdot 1$ & $1 \cdot 0$ & $2 \cdot 7$ & $0 \cdot 8$ & $2 \cdot 6$ & $1 \cdot 0$ & $2 \cdot 0$ \\
\hline Folate $(\mu \mathrm{g})$ & $476 \cdot 4$ & $190 \cdot 7$ & $744 \cdot 2$ & $399 \cdot 9$ & $786 \cdot 1$ & $479 \cdot 7$ & - \\
\hline Vitamin $B_{12}(\mu \mathrm{g})$ & $4 \cdot 5$ & $2 \cdot 9$ & $5 \cdot 1$ & $2 \cdot 8$ & $4 \cdot 6$ & $2 \cdot 5$ & $4 \cdot 4$ \\
\hline Vitamin C (mg) & $117 \cdot 9$ & $54 \cdot 1$ & $202 \cdot 0$ & $91 \cdot 9$ & $200 \cdot 6$ & $110 \cdot 7$ & $107 \cdot 0$ \\
\hline Vitamin E (mg) & $10 \cdot 9$ & $4 \cdot 5$ & $12 \cdot 9$ & $4 \cdot 2$ & $12 \cdot 7$ & $4 \cdot 8$ & $11 \cdot 0$ \\
\hline $\mathrm{Ca}(\mathrm{mg})$ & $961 \cdot 5$ & $309 \cdot 1$ & $822 \cdot 9$ & $292 \cdot 8$ & $805 \cdot 2$ & $281 \cdot 5$ & $884 \cdot 0$ \\
\hline $\mathrm{K}(\mathrm{mg})$ & $3780 \cdot 7$ & $990 \cdot 1$ & $4382 \cdot 1$ & $1307 \cdot 7$ & $4322 \cdot 4$ & $1490 \cdot 7$ & $3262 \cdot 0$ \\
\hline $\mathrm{Fe}(\mathrm{mg})$ & $16 \cdot 8$ & $7 \cdot 3$ & $19 \cdot 3$ & $6 \cdot 6$ & $19 \cdot 4$ & $7 \cdot 6$ & $12 \cdot 1$ \\
\hline Se $(\mu g)$ & $56 \cdot 9$ & $27 \cdot 5$ & $68 \cdot 8$ & $29 \cdot 9$ & $66 \cdot 5$ & $30 \cdot 6$ & $62 \cdot 4$ \\
\hline $\mathrm{Na}(\mathrm{mg})$ & $2761 \cdot 2$ & $897 \cdot 7$ & $3434 \cdot 8$ & $1449 \cdot 7$ & $3440 \cdot 7$ & $1577 \cdot 1$ & - \\
\hline $\mathrm{Mg}(\mathrm{mg})$ & $402 \cdot 2$ & $128 \cdot 8$ & $434 \cdot 5$ & $131 \cdot 0$ & $436 \cdot 4$ & $159 \cdot 7$ & - \\
\hline $\mathrm{Zn}(\mathrm{mg})$ & $11 \cdot 7$ & $3 \cdot 2$ & $13 \cdot 2$ & $4 \cdot 1$ & $12 \cdot 7$ & $4 \cdot 2$ & $11 \cdot 4$ \\
\hline
\end{tabular}

8dWDR, $8 \mathrm{~d}$ weighed diet record; FFQtime1, first administration of the FFQ developed in the present study; FFQtime2, second FFQ administration. *Supplement data not included.

+Mean dietary intakes among 2239 New Zealanders aged 31-70 years, as reported in the 2008/09 New Zealand Adult Nutrition Survey report using one $24 \mathrm{~h}$ recall $^{(15)}$.

$\alpha$-tocopherol. SCC for the relative validity of the FFQ and the 8dWDR compared with blood biomarkers are shown in Table 5. For energy-adjusted intake of $\beta$-carotene and vitamin $C$, these SCC were respectively 0.34 and 0.33 with the FFQ, 0.30 and 0.38 with the $8 \mathrm{dWDR}$; but no correlation was observed for vitamin $\mathrm{E}$.

\section{Discussion}

In the present study we assessed the reliability and validity of a semi-quantitative FFQ in a sample of free-living NZ adults. The results show that the FFQ provides highly repeatable measurements and good relative validity for ranking individuals by nutrient intake.

\section{Test-retest reliability}

Reliability of the FFQ was generally good to excellent, with most reliability coefficients falling at the upper end of, or exceeding, the commonly reported range of $0 \cdot 5-0 \cdot 7^{(5,7)}$. Previous studies of FFQ designed to capture intake over the past 12 months have shown higher reliability coefficients when repeat administrations of the FFQ have been at intervals of 6 months or less apart, compared with FFQ which were repeat-administered over a longer time period ${ }^{(7)}$. This relatively high reliability at a short-term interval could be attributed to learning or memory effects ${ }^{(20)}$. Due to time and budget constraints, the present study adopted a 9-month interval that was considered sufficient to dilute learning effects while still capturing a time period over which habitual dietary changes are unlikely to be made ${ }^{(8)}$.

It is important to acknowledge that FFQ replicates obtained in different seasons, separated by a 9-month interval as in the current study, may yield less reproducible measures than FFQ collected in the same season one year apart. As documented in previous research, the present study found that energy intake from FFQ collected during winter was higher than that collected in other seasons (data not shown) ${ }^{(21-26)}$. Seasonal price fluctuations in fruits, vegetables and dairy foods in $\mathrm{NZ}^{(27)}$ might alter food choices and corresponding nutrient intakes (e.g. vitamins A, C and $\mathrm{E})^{(28)}$. Despite potential seasonal changes in food intake, our FFQ showed comparable reliability for energy and nutrient intakes to previous FFQ that were designed to investigate intake over a year ${ }^{(29-32)}$.

As the aim of the FFQ and the design of validation studies (e.g. time interval between administrations) have 
Table 2 Intra-class correlation coefficients (ICC)* and Spearman correlation coefficients (SCC)† for crude and energy-adjusted nutrient intakes from the present study, compared with results from previous studies with similar study design

\begin{tabular}{|c|c|c|c|c|c|c|}
\hline \multirow[b]{3}{*}{ Nutrient } & \multirow{2}{*}{\multicolumn{2}{|c|}{ Reliability (ICC) }} & \multicolumn{4}{|c|}{ Relative validity (SCC) } \\
\hline & & & \multicolumn{2}{|c|}{ Crude } & \multicolumn{2}{|c|}{ Energy-adjusted } \\
\hline & Present study & Previous studies $¥$ & Present study & Previous studies $\S$ & Present study & Previous studies $\S$ \\
\hline Energy & 0.55 & $0.39-0.73$ & 0.25 & $0 \cdot 17-0 \cdot 70$ & - & - \\
\hline Protein & 0.57 & $0.40-0.74$ & 0.29 & $0.14-0.62$ & 0.43 & $0.14-0.63$ \\
\hline Total fat & 0.54 & $0.42-0.76$ & $0 \cdot 27$ & $0 \cdot 17-0.76$ & $0 \cdot 37$ & $0.06-0.65$ \\
\hline SFA & 0.52 & $0.42-0.71$ & $0 \cdot 37$ & $0 \cdot 27-0.74$ & $0 \cdot 37$ & $0 \cdot 14-0.71$ \\
\hline MUFA & 0.56 & $0.44-0.74$ & 0.23 & $0.34-0.74$ & 0.44 & $-0.05-0.62$ \\
\hline PUFA & 0.65 & $0.43-0.68$ & $0 \cdot 26$ & $0 \cdot 16-0.71$ & $0 \cdot 39$ & $0.12-0.63$ \\
\hline Cholesterol & 0.73 & $0.49-0.71$ & 0.60 & $0.20-0.67$ & 0.65 & $0.14-0.67$ \\
\hline Carbohydrate & 0.57 & $0.44-0.74$ & 0.35 & $0.16-0.60$ & 0.56 & $0.12-0.69$ \\
\hline Sucrose & $0 \cdot 70$ & $0.49-0.71$ & 0.47 & $-0 \cdot 18-0 \cdot 60$ & 0.46 & $0.43-0.54$ \\
\hline Fructose & $0 \cdot 65$ & - & 0.38 & - & 0.55 & - \\
\hline Fibre & 0.63 & $0.43-0.82$ & $0 \cdot 39$ & $0.06-0.57$ & 0.43 & $0.23-0.64$ \\
\hline Alcohol & $0 \cdot 83$ & $0.69-0.99$ & $0 \cdot 74$ & $0.42-0.94$ & 0.74 & $0.40-0.93$ \\
\hline Total vitamin A & 0.56 & $0.47-0.69$ & 0.35 & $0.08-0.35$ & 0.39 & $0 \cdot 10-0 \cdot 41$ \\
\hline$\beta$-Carotene & $0 \cdot 64$ & $0.48-0.78$ & 0.48 & $0 \cdot 30-0.60$ & 0.58 & $0.32-0.62$ \\
\hline Thiamin & 0.73 & $0.46-0.78$ & $0 \cdot 40$ & $-0.03-0.55$ & 0.41 & $-0.01-0.54$ \\
\hline Riboflavin & $0 \cdot 71$ & $0.59-0.84$ & $0 \cdot 13$ & $0.21-0.64$ & 0.54 & $0.38-0.58$ \\
\hline Niacin equivalents & 0.69 & $0.60-0.72$ & 0.25 & $0.26-0.58$ & 0.34 & $0.15-0.42$ \\
\hline Vitamin $\mathrm{B}_{6}$ & 0.72 & $0.40-0.79$ & 0.27 & $0.15-0.59$ & 0.36 & $-0.12-0.65$ \\
\hline Folate & 0.73 & $0.55-0.87$ & 0.38 & $0.07-0.50$ & 0.52 & $0.15-0.63$ \\
\hline Vitamin $B_{12}$ & $0 \cdot 61$ & $0.60-0.69$ & $0 \cdot 40$ & $0.40-0.54$ & 0.47 & $0.40-0.53$ \\
\hline Vitamin C & $0 \cdot 72$ & $0.55-0.81$ & $0 \cdot 41$ & $0.45-0.53$ & 0.56 & $0.51-0.67$ \\
\hline Vitamin E & 0.64 & $0.47-0.84$ & 0.31 & $0.44-0.53$ & 0.24 & $0.40-0.49$ \\
\hline $\mathrm{Ca}$ & 0.47 & $0.41-0.76$ & $0 \cdot 11$ & $0.27-0.65$ & 0.28 & $0.32-0.67$ \\
\hline $\mathrm{K}$ & 0.67 & $0.49-0.77$ & $0 \cdot 18$ & $0.15-0.56$ & 0.30 & $0.18-0.67$ \\
\hline $\mathrm{Fe}$ & 0.67 & $0.42-0.81$ & 0.26 & $0.06-0.64$ & 0.53 & $0.28-0.78$ \\
\hline $\mathrm{Se}$ & 0.68 & - & 0.50 & $0.37-0.53$ & 0.46 & 0.42 \\
\hline $\mathrm{Na}$ & 0.67 & $0.65-0.72$ & 0.36 & $0.21-0.52$ & 0.27 & $0.19-0.52$ \\
\hline $\mathrm{Mg}$ & 0.66 & $0.62-0.70$ & 0.32 & $0.40-0.58$ & 0.52 & $0.49-0.66$ \\
\hline $\mathrm{Zn}$ & 0.53 & $0.53-0.65$ & 0.20 & $0.19-0.56$ & 0.24 & $0 \cdot 13-0 \cdot 70$ \\
\hline
\end{tabular}

8dWDR, $8 \mathrm{~d}$ weighed diet record.

*ICC between administrations of the FFQ repeated nine months apart.

tSCC of the FFQ $v$. the 8dWDR. Supplement data not included.

$\ddagger$ The range of correlation coefficients from previous reliability studies of self-administered, multi-nutrient FFQ that were administered twice at least 6 months apart. Study selection was based on the similarity of FFQ design and the mode of administration, as compared with the FOOD study ${ }^{(12,29,31,32,34-38)}$

$\S$ The range of correlation coefficients derived from relative validation studies of self-administered, multi-nutrient FFQ of similar design ${ }^{(9-13,29,31,34,35,37,39-45)}$.

been shown to influence reliability ${ }^{(7,33)}$, it is appropriate to compare findings of the current study with those of previous studies using FFQ that are most similar in content, aim and administration. Compared with several versions of the Willett FFQ and the UK-EPIC FFQ that were repeatadministered at least 6 months apart in free-living adults, the current FFQ provided highly comparable reliability coefficients for most nutrients ${ }^{(12,29,31,32,34-38)}$. For vitamin C, our FFQ appeared to be more reliable than various forms of the Willett $\mathrm{FFQ}^{(29,31,32,34-36,38)}$ and showed similar reliability to the UK-EPIC FFQ ${ }^{(37)}$. These results indicate that a single administration of the FFQ is sufficient to provide nutrient measures with a high level of reliability.

\section{Relative validity}

The present study is the first to use a weighed diet record and biomarkers to evaluate the validity of a multi-nutrient FFQ for use in NZ adults. Among FFQ designed to assess intake of multiple nutrients in NZ adults over a 12-month period, only three have been evaluated for validity ${ }^{(9,10,12)}$. All of these FFQ were validated against an estimated diet record that was collected on consecutive days over only 1 month. The coverage of a 1-month period and the use of consecutive days may not be sufficient to capture dayto-day and seasonal variations in dietary intake over a year, as measured by these FFQ. The use of estimated diet records also requires portion size estimation, which would result in correlated errors ${ }^{(5)}$. In contrast, weighed diet records have been credited as an ideal validation reference due to the advantages of direct weighing ${ }^{(5)}$. In the present study, the 8dWDR that covered all days in a week, over four seasons in a year, would capture as much dietary variation as possible. Thus, the 8dWDR is likely to represent habitual dietary intake and offers an optimal validity evaluation of the FFQ.

When compared with the 8dWDR, the FFQ showed acceptable to good validity with most SCC lying within the commonly observed range of $0 \cdot 3-0 \cdot 7^{(5,8)}$. The validity coefficients were comparable to those found in previous studies using similar $\mathrm{FFQ}^{(9-13,29,31,34,35,37,39-45)}$. After energy adjustment, our reported coefficients for cholesterol, $\beta$-carotene and vitamin $\mathrm{E}$ lay at the upper end of the 
Table 3 Cross-classification of individuals by quartiles of nutrient intakes between the FFQ and the 8dWDR (males and females aged 30-59 years ( $n$ 132), Dunedin, New Zealand, 2009-2010)

\begin{tabular}{|c|c|c|c|c|}
\hline \multirow[b]{2}{*}{ Nutrient } & \multicolumn{2}{|c|}{ Crude } & \multicolumn{2}{|c|}{ Energy-adjusted } \\
\hline & $\begin{array}{c}\text { Correct } \\
\text { classification (\%) }\end{array}$ & $\begin{array}{c}\text { Gross } \\
\text { misclassification (\%)† }\end{array}$ & $\begin{array}{c}\text { Correct } \\
\text { classification (\%)* }\end{array}$ & $\begin{array}{c}\text { Gross } \\
\text { misclassification (\%)† }\end{array}$ \\
\hline Energy & $74 \cdot 2$ & $8 \cdot 3$ & - & - \\
\hline Protein & $71 \cdot 2$ & $6 \cdot 8$ & $76 \cdot 5$ & $7 \cdot 6$ \\
\hline Total fat & $72 \cdot 0$ & $10 \cdot 6$ & $75 \cdot 0$ & $6 \cdot 1$ \\
\hline SFA & $77 \cdot 3$ & $6 \cdot 8$ & $81 \cdot 8$ & $3 \cdot 8$ \\
\hline MUFA & $70 \cdot 5$ & $9 \cdot 9$ & $73 \cdot 5$ & $8 \cdot 3$ \\
\hline PUFA & $71 \cdot 2$ & $8 \cdot 3$ & $78 \cdot 8$ & $3 \cdot 0$ \\
\hline Cholesterol & $86 \cdot 4$ & $3 \cdot 0$ & $84 \cdot 8$ & $2 \cdot 3$ \\
\hline Carbohydrate & $73 \cdot 5$ & $6 \cdot 1$ & $82 \cdot 6$ & $2 \cdot 3$ \\
\hline Sucrose & $77 \cdot 3$ & $4 \cdot 6$ & $75 \cdot 0$ & $5 \cdot 3$ \\
\hline Fructose & $75 \cdot 0$ & $6 \cdot 8$ & $80 \cdot 3$ & $5 \cdot 3$ \\
\hline Fibre & $78 \cdot 1$ & $5 \cdot 3$ & $81 \cdot 1$ & $3 \cdot 0$ \\
\hline Alcohol & $97 \cdot 0$ & 0.8 & $91 \cdot 3$ & 0.0 \\
\hline Total vitamin A & $71 \cdot 2$ & $6 \cdot 1$ & $77 \cdot 3$ & $4 \cdot 6$ \\
\hline$\beta$-Carotene & $78 \cdot \overline{8}$ & 1.5 & $80 \cdot 3$ & 0.0 \\
\hline Thiamin & $78 \cdot 8$ & $5 \cdot 3$ & $75 \cdot 8$ & $2 \cdot 3$ \\
\hline Riboflavin & $68 \cdot 9$ & $12 \cdot 1$ & $76 \cdot 5$ & $5 \cdot 3$ \\
\hline Niacin equivalents & $72 \cdot 0$ & $9 \cdot 1$ & $71 \cdot 2$ & $9 \cdot 1$ \\
\hline Vitamin $\mathrm{B}_{6}$ & $69 \cdot 7$ & $6 \cdot 1$ & $75 \cdot 0$ & $5 \cdot 3$ \\
\hline Folate & $75 \cdot 0$ & $3 \cdot 0$ & $72 \cdot 7$ & $3 \cdot 8$ \\
\hline Vitamin $B_{12}$ & $76 \cdot 5$ & $3 \cdot 0$ & $79 \cdot 5$ & $5 \cdot 3$ \\
\hline Vitamin C & $77 \cdot 3$ & $4 \cdot 6$ & $82 \cdot 6$ & $3 \cdot 0$ \\
\hline Vitamin E & $78 \cdot 0$ & $7 \cdot 6$ & $82 \cdot 6$ & $2 \cdot 3$ \\
\hline $\mathrm{Ca}$ & $65 \cdot 9$ & $12 \cdot 1$ & $72 \cdot 0$ & $6 \cdot 8$ \\
\hline $\mathrm{K}$ & $69 \cdot 0$ & $9 \cdot 9$ & $77 \cdot 3$ & $4 \cdot 6$ \\
\hline $\mathrm{Fe}$ & $72 \cdot 7$ & $9 \cdot 1$ & $75 \cdot 0$ & $5 \cdot 3$ \\
\hline $\mathrm{Se}$ & $85 \cdot 6$ & $6 \cdot 8$ & $75 \cdot 8$ & $7 \cdot 6$ \\
\hline $\mathrm{Na}$ & $75 \cdot 0$ & $3 \cdot 8$ & $79 \cdot 6$ & $3 \cdot 0$ \\
\hline $\mathrm{Mg}$ & $72 \cdot 7$ & $5 \cdot 3$ & $75 \cdot 8$ & $3 \cdot 8$ \\
\hline $\mathrm{Zn}$ & $72 \cdot 0$ & $9 \cdot 9$ & $71 \cdot 2$ & $6 \cdot 8$ \\
\hline
\end{tabular}

8dWDR, $8 \mathrm{~d}$ weighed diet record.

*Percentage of participants classified into the same or adjacent quartiles of nutrient intake (supplement data not included). tPercentage of participants grossly classified into extreme quartiles of nutrient intake (supplement data not included).

range observed in various forms of the Willett FFQ and the UK-EPIC FFQ ${ }^{(29,31,34,35,39-45)}$. High validity coefficients were also observed for cholesterol, vitamin A, $\beta$-carotene, folate, vitamin $\mathrm{C}$ and vitamin $\mathrm{E}$ in comparison with previous NZ FFQ ${ }^{(9-13)}$.

Our FFQ also showed a comparable level of validity to previous findings when compared against biomarkers. The validity coefficients for our FFQ fell within previously reported ranges for $\beta$-carotene $e^{(10,30,41,42,46-51)}$, vitamin $\mathrm{C}^{(47,50,52-55)}$ and vitamin $\mathrm{E}$ (correlation coefficient $=$ $-0 \cdot 20-0 \cdot 45)^{(41,46,48,51,55-67)}$. The low validity coefficient for vitamin $\mathrm{E}$ reported in the present study could be explained by between-subject differences in metabolism of $\alpha$-tocopherol ${ }^{(68)}$. Adjustment for blood cholesterol concentration, which is correlated to serum $\alpha$-tocopherol, has been shown to increase the validity coefficient between intake and blood concentration of vitamin $\mathrm{E}^{(46,57,63)}$. Measures of blood cholesterol are currently not available in the present study, but as blood samples have been frozen this is a possibility for further analysis. We also collected only a single blood sample due to budget constraints. Although a single measure of blood biomarkers might be less likely to reflect year-round nutrient intake than multiple measurements, biomarkers can offer an objective measure of the corresponding nutrient intake ${ }^{(69)}$. This is why biomarkers have been credited as a superior complementary method for validation of $\mathrm{FFQ}^{(69)}$, even though they reflect intake and utilisation of nutrients, rather than intake per $s e^{(68)}$.

Since correlation coefficients measure association rather than absolute agreement between measurements using two methods, an international group of experts has advocated the use of the Bland-Altman method as a complementary aid in FFQ validation ${ }^{(7)}$. Results of our study showed an acceptable agreement between methods for most macronutrients, whereas wide LOA were observed for micronutrients such as $\beta$-carotene, thiamin and vitamin C. Similar findings have been consistently reported in studies using diet records to validate FFQ in free-living adults ${ }^{(44,70-74)}$. Results of previous FFQ validation studies that have used the Bland-Altman method have produced LOA outside the range of 50-250\% for vitamin $C^{(70-72,74)}$. An Australian version of the Willett FFQ has produced $\beta$-carotene estimates ranging from $28 \%$ lower to $790 \%$ higher than that produced by a $12 \mathrm{~d}$ diet record ${ }^{(44)}$. These consistent findings indicate that wide LOA between FFQ and diet records are not unusual, highlighting the difficulty in obtaining absolute measures of certain nutrients using an FFQ. 
Table 4 Strength of agreement using the Bland-Altman method between nutrient intakes derived from the FFQ and the 8dWDR (males and females aged 30-59 years ( $n$ 132), Dunedin, New Zealand, 2009-2010)

\begin{tabular}{|c|c|c|c|c|c|c|}
\hline \multirow[b]{2}{*}{ Nutrient } & \multicolumn{3}{|c|}{ Crude } & \multicolumn{3}{|c|}{ Energy-adjusted } \\
\hline & Mean $(\%)^{\star}$ & $95 \% \mathrm{Cl}$ & LOA (\%)† & Mean $(\%)^{\star}$ & $95 \% \mathrm{Cl}$ & LOA $(\%) \dagger$ \\
\hline Energy & 102 & 96,108 & 53-195 & - & - & - \\
\hline Protein & 99 & 94,105 & $52-189$ & 99 & 97,102 & $73-134$ \\
\hline Total fat & 103 & 96,110 & $47-225$ & 103 & 100,106 & $72-147$ \\
\hline SFA & 109 & 102,117 & $48-246$ & 109 & 105,114 & $67-176$ \\
\hline MUFA & 103 & 95,110 & $44-239$ & 103 & 99,107 & $65-161$ \\
\hline PUFA & 96 & 89,104 & $40-229$ & 96 & 92,101 & $57-164$ \\
\hline Cholesterol & 99 & 91,107 & $39-250$ & 99 & 92,106 & $43-226$ \\
\hline Carbohydrate & 103 & 97,109 & $52-204$ & 103 & 101,105 & $79-135$ \\
\hline Sucrose & 126 & 117,137 & $50-317$ & 126 & 119,134 & $64-251$ \\
\hline Fructose & 140 & 129,151 & $56-347$ & 140 & 132,148 & $70-278$ \\
\hline Fibre & 126 & 118,134 & $58-274$ & 126 & 121,131 & $79-200$ \\
\hline Alcohol & 136 & 109,169 & $11-1679$ & 136 & 110,169 & $11-1641$ \\
\hline Total vitamin A & 140 & 128,153 & $48-403$ & 140 & 130,151 & $58-337$ \\
\hline$\beta$-Carotene & 166 & 149,185 & $47-591$ & 166 & 151,183 & $55-505$ \\
\hline Thiamin & 146 & 131,162 & $42-511$ & 146 & 133,159 & $52-412$ \\
\hline Riboflavin & 125 & 113,138 & $39-403$ & 125 & 116,135 & $50-310$ \\
\hline Niacin equivalents & 113 & 106,121 & $53-240$ & 113 & 109,118 & $72-178$ \\
\hline Vitamin $\mathrm{B}_{6}$ & 125 & 117,135 & 53-295 & 125 & 119,133 & $67-235$ \\
\hline Folate & 150 & 136,165 & $50-447$ & 150 & 139,161 & $64-350$ \\
\hline Vitamin $B_{12}$ & 105 & 96,116 & $35-318$ & 105 & 97,114 & $42-265$ \\
\hline Vitamin $\mathrm{C}$ & 164 & 149,180 & $55-486$ & 164 & 152,176 & $71-377$ \\
\hline Vitamin E & 116 & 108,124 & $51-264$ & 116 & 111,121 & 69-194 \\
\hline $\mathrm{Ca}$ & 83 & 77,89 & 35-197 & 83 & 79,87 & $47-146$ \\
\hline $\mathrm{K}$ & 111 & 104,119 & $52-238$ & 111 & 108,115 & $75-166$ \\
\hline $\mathrm{Fe}$ & 115 & 107,125 & $47-282$ & 115 & 110,121 & $66-203$ \\
\hline $\mathrm{Se}$ & 117 & 108,126 & $49-280$ & 117 & 110,125 & $56-244$ \\
\hline $\mathrm{Na}$ & 119 & 110,128 & $49-290$ & 119 & 113,125 & $68-206$ \\
\hline $\mathrm{Mq}$ & 107 & 100,114 & 50-229 & 107 & 103,111 & 69-165 \\
\hline $\mathrm{Zn}$ & 106 & 100,113 & $51-223$ & 106 & 103,110 & $71-159$ \\
\hline
\end{tabular}

$8 \mathrm{dWDR}, 8 \mathrm{~d}$ weighed diet record; LOA, limits of agreement.

${ }^{*}$ Mean $\%$ agreement $=$ (nutrient intake of FFQ/nutrient intake of $\left.8 \mathrm{dWDR}\right) \times 100 \%$.

tThe width of the LOA represents the range in which $95 \%$ of the differences between the FFQ and the 8dWDR are expected to fall.

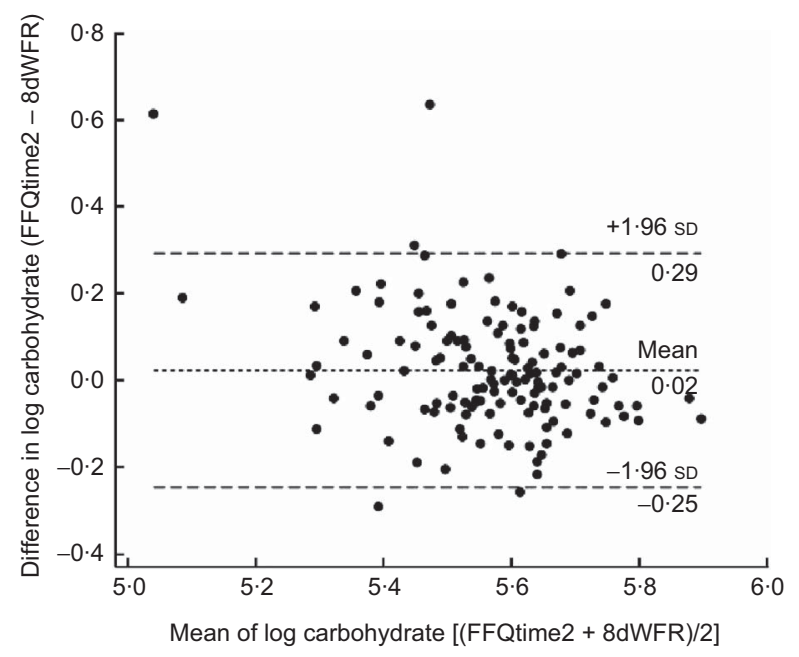

Fig. 1 Bland-Altman plot showing the relative validity of energy-adjusted carbohydrate from the second FFQ administration (FFQtime2) $v$. the $8 \mathrm{~d}$ weighed diet record (8dWDR), based on log-transformed values $(---$, limits of agreement; - - -, mean difference)

Nevertheless, as is the case with most FFQ, our FFQ was designed to rank individuals according to their nutrient intake. Study results demonstrated that the FFQ fulfilled its
Table 5 Spearman correlation coefficients $(\mathrm{SCC})^{*}$ for relative validity of the FFQ and the 8dWDR compared with blood biomarkerst for $\beta$-carotene, vitamin $\mathrm{C}$ and vitamin $\mathrm{E}$ (males and females aged $30-59$ years (n 132), Dunedin, New Zealand, 2009-2010)

\begin{tabular}{lrcrrr}
\hline & \multicolumn{3}{c}{ Relative validity (SCC) } \\
\cline { 2 - 3 } \cline { 5 - 6 } Nutrient & Crude & Energy-adjusted & & Crude & Energy-adjusted \\
\cline { 2 - 3 } \cline { 5 - 6 } Vitamin C & 0.26 & 0.33 & & 0.37 & 0.38 \\
Vitamin E & -0.19 & -0.10 & & -0.08 & 0.00 \\
$\beta$-Carotene & 0.30 & 0.34 & & 0.29 & 0.30 \\
\hline
\end{tabular}

8dWDR, 8d weighed diet record.

${ }^{*} \mathrm{SCC}$ for total nutrient intake including relevant supplement data.

tBiomarker of vitamin $C$ is plasma ascorbic acid $(\mu \mathrm{mol} / \mathrm{l})$, of vitamin $E$ is serum $\alpha$-tocopherol $(\mu \mathrm{mol} / \mathrm{l})$ and of $\beta$-carotene is serum $\beta$-carotene $(\mu \mathrm{mol} / \mathrm{l})$, compared against dietary intake of vitamin $C(\mathrm{mg})$, vitamin $E(\mathrm{mg})$ and $\beta$-carotene $(\mu \mathrm{g})$, respectively.

purpose, as shown by high agreement with the 8dWDR and a very low proportion of gross misclassification for all nutrient intakes. This allows us to distinguish between individuals with high and low intake of individual nutrients, the focus of many epidemiological studies.

One of the challenges in conducting a dietary validation study is the ability to recruit a representative sample of the target population. The mean intakes of energy and nutrients 
of the participants in our study were comparable to the nationally representative ANS data ${ }^{(15)}$, even though our participants might not be nationally representative with respect to ethnicity. Those of Maori or Pacific Island descent composed less than $5 \%$ of our participants, which is lower than the $22 \%$ documented in the latest NZ census report ${ }^{(75)}$. Maori and Pacific Islanders are more likely to have higher $\mathrm{BMI}^{(15)}$ and different dietary patterns compared with those of European and other ethnicity ${ }^{(76,77)}$. Therefore, future evaluation would be necessary prior to the use of the FFQ in studies focusing on Maori or Pacific Island populations.

\section{Conclusion}

The present study provides a thorough evaluation of both reliability and validity of the FFQ, and shows the ability of the FFQ in providing repeatable measures and in ranking individuals by their nutrient intake. The FFQ will be a useful tool to assess the nutrient intake of NZ adults in future research, particularly in studies investigating relationships between diet and disease.

\section{Acknowledgements}

Sources of funding: The study was funded by the University of Otago. Conflicts of interest: The authors have no conflicts of interest. Authors' contributions: P.M.L.S. and S.S. were the principal investigators for the study and were responsible for the study conception, FFQ development and study design. C.H.Y.S. was responsible for management of data collection and processing, data analysis and writing the first draft of the manuscript. All authors critically revised the manuscript and have read and approved the final version. Acknowledgements: The authors thank Andrew Gray from the Department of Preventive and Social Medicine for his statistical advice and the Adult Nutrition Survey Team for its assistance with developing the nutrient database for the FFQ. They also thank all FOOD study participants and everyone involved in the collection and processing of data.

\section{References}

1. Alwan A (2011) Global Status Report On Noncommunicable Diseases 2010. Geneva: WHO Press.

2. Chiuve SE, Sampson L \& Willett WC (2011) The association between a nutritional quality index and risk of chronic disease. Am J Prev Med 40, 505-513.

3. Gonzalez CA (2006) The European Prospective Investigation into Cancer and Nutrition (EPIC). Public Health Nutr 9 , 124-126.

4. Thompson FE \& Subar AF (2008) Dietary assessment methodology. In Nutrition in the Prevention and Treatment of Disease, 2nd ed., pp. 3-30 [AM Coulston and C Boushey, editors]. San Diego, CA: Elsevier Academic Press.

5. Willett W (1998) Nutritional Epidemiology. New York: Oxford University Press.

6. Gibson RS (2005) Principles of Nutritional Assessment. New York: Oxford University Press.
7. Cade JE, Burley VJ, Warm DL et al. (2004) Food-frequency questionnaires: a review of their design, validation and utilisation. Nutr Res Rev 17, 5-22.

8. Cade J, Thompson R, Burley V et al. (2002) Development, validation and utilisation of food-frequency questionnaires a review. Public Health Nutr 5, 567-587.

9. Sharpe SJ, Page NA, Gamble GD et al. (1993) Validation of a food frequency questionnaire for use in cardiovascular risk factor studies in New Zealand. Proc Nutr Soc N Z 18, 90-100.

10. Marshall R (1994) The design, analysis and evaluation of a food frequency questionnaire for assessing the nutrient intake of New Zealand adults. MSc Thesis, University of Otago.

11. Bolch R (1994) The validity of a food frequency questionnaire in assessing the nutrient intake of New Zealand adults. MSc Thesis, University of Otago.

12. Metcalf P, Swinburn B, Scragg R et al. (1997) Reproducibility and validity of a food frequency questionnaire in European and Polynesian New Zealanders. Ethn Health 2, 297-308.

13. Bell AC, Swinburn BA, Amosa $\mathrm{H}$ et al. (1999) The impact of modernisation on the diets of adults aged 20-40 years from Samoan church communities in Auckland. Asia Pac J Public Health 11, 4-9.

14. Russell DG, Parnell WR, Wilson NC et al. (1999) NZ Food: NZ People. Key Results of the 1997 National Nutrition Survey. Wellington: Ministry of Health.

15. University of Otago \& Ministry of Health (2011) A Focus on Nutrition: Key Findings of the 2008/09 New Zealand Adult Nutrition Survey. Wellington: Ministry of Health.

16. Vuilleumier JP \& Keck E (1989) Fluorometric assay of vitamin $C$ in biological materials using a centrifugal analyser with fluorescence attachment. J Micronutr Anal 5, 25-34.

17. Thurnham DI, Smith E \& Flora PS (1988) Concurrent liquid-chromatographic assay of retinol, $\alpha$-tocopherol, $\beta$-carotene, $\alpha$-carotene, lycopene, and $\beta$-cryptoxanthin in plasma, with tocopherol acetate as internal standard. Clin Chem 34, 377-381.

18. Willett WC, Howe GR \& Kushi LH (1997) Adjustment for total energy intake in epidemiologic studies. Am J Clin Nutr 65, 4 Suppl., 1220S-1231S.

19. Bland JM \& Altman DG (1999) Measuring agreement in method comparison studies. Stat Methods Med Res 8 , $135-160$.

20. Horwath CC (1990) Food frequency questionnaires: a review. Aust J Nutr Diet 47, 71-76.

21. Capita R \& Alonso-Calleja C (2005) Differences in reported winter and summer dietary intakes in young adults in Spain. Int J Food Sci Nutr 56, 431-443.

22. Shahar DR, Yerushalmi N, Lubin F et al. (2001) Seasonal variations in dietary intake affect the consistency of dietary assessment. Eur J Epidemiol 17, 129-133.

23. Fowke JH, Schlundt D, Gong Y et al. (2004) Impact of season of food frequency questionnaire administration on dietary reporting. Ann Epidemiol 14, 778-785.

24. Tokudome Y, Kuriki K, Imaeda N et al. (2003) Seasonal variation in consumption and plasma concentrations of fatty acids in Japanese female dietitians. Eur J Epidemiol 18, 945-953.

25. Ma Y, Olendzki BC, Li W et al. (2005) Seasonal variation in food intake, physical activity, and body weight in a predominantly overweight population. Eur J Clin Nutr 60, 519-528.

26. de Castro JM (1991) Seasonal rhythms of human nutrient intake and meal pattern. Physiol Behav 50, 243-248.

27. Bascand G (2011) Food Price Index: February 2011. Wellington: Statistics New Zealand.

28. Contento IR (2008) Nutrition education: linking research, theory, and practice. Asia Pac J Clin Nutr 17, 176-179. 
29. Willett WC, Sampson L, Stampfer MJ et al. (1985) Reproducibility and validity of a semiquantitative food frequency questionnaire. Am J Epidemiol 122, 51-56.

30. Katsouyanni K, Rimm EB, Gnardellis C et al. (1997) Reproducibility and relative validity of an extensive semiquantitative food frequency questionnaire using dietary records and biochemical markers among Greek schoolteachers. Int J Epidemiol 26, Suppl. 1, S118-S127.

31. Longnecker MP, Lissner L, Holden JM et al. (1993) The reproducibility and validity of a self-administered semiquantitative food frequency questionnaire in subjects from South Dakota and Wyoming. Epidemiology 4, 356-365.

32. Ajani UA, Willett WC \& Seddon JM (1994) Reproducibility of a food frequency questionnaire for use in ocular research. Eye Disease Case-Control Study Group. Invest Ophthalmol Vis Sci 35, 2725-2733.

33. Molag ML, de Vries JHM, Ocké MC et al. (2007) Design characteristics of food frequency questionnaires in relation to their validity. Am J Epidemiol 166, 1468-1478.

34. Willett WC, Sampson L, Browne ML et al. (1988) The use of a self-administered questionnaire to assess diet four years in the past. Am J Epidemiol 127, 188-199.

35. Rimm EB, Giovannucci EL, Stampfer MJ et al. (1992) Reproducibility and validity of an expanded self-administered semiquantitative food frequency questionnaire among male health professionals. Am J Epidemiol 135, 1114-1126.

36. Munger RG, Folsom AR, Kushi LH et al. (1992) Dietary assessment of older Iowa women with a food frequency questionnaire: nutrient intake, reproducibility, and comparison with 24-hour dietary recall interviews. $A m J$ Epidemiol 136, 192-200.

37. McKeown NM, Day NE, Welch AA et al. (2001) Use of biological markers to validate self-reported dietary intake in a random sample of the European Prospective Investigation into Cancer United Kingdom Norfolk cohort. Am J Clin Nutr 74, 188-196.

38. Ibiebele TI, Parekh S, Mallitt K et al. (2009) Reproducibility of food and nutrient intake estimates using a semiquantitative FFQ in Australian adults. Public Health Nutr 12, 2359-2365.

39. Willett WC, Reynolds RD, Cottrell-Hoehner S et al. (1987) Validation of a semi-quantitative food frequency questionnaire: comparison with a 1-year diet record. J Am Diet Assoc 87, 43-47.

40. Bingham SA, Gill C, Welch A et al. (1994) Comparison of dietary assessment methods in nutritional epidemiology: weighed records $v .24 \mathrm{~h}$ recalls, food frequency questionnaires and estimated diet records. Br J Nutr 72, 619-643.

41. Brunner E, Stallone D, Juneja M et al. (2001) Dietary assessment in Whitehall II: comparison of $7 \mathrm{~d}$ diet diary and food-frequency questionnaire and validity against biomarkers. Br J Nutr 86, 405-414.

42. McNaughton SA, Marks GC, Gaffney P et al. (2005) Validation of a food-frequency questionnaire assessment of carotenoid and vitamin $\mathrm{E}$ intake using weighed food records and plasma biomarkers: the method of triads model. Eur J Clin Nutr 59, 211-218.

43. Nath SD \& Huffman FG (2005) Validation of a semiquantitative food frequency questionnaire to assess energy and macronutrient intakes of Cuban Americans. Int I Food Sci Nutr 56, 309-314.

44. Marks GC, Hughes MC \& Van Der Pols JC (2006) The effect of personal characteristics on the validity of nutrient intake estimates using a food-frequency questionnaire. Public Health Nutr 9, 394-402.

45. Itzhaki D, Rennert HS, Rosen G et al. (2008) Validity and reproducibility of a semi-quantitative food frequency questionnaire adapted to an Israeli population. Open Nutr J 2, 9-14.
46. Ascherio A, Stampfer MJ, Colditz GA et al. (1992) Correlations of vitamin $\mathrm{A}$ and $\mathrm{E}$ intakes with the plasma concentrations of carotenoids and tocopherols among American men and women. J Nutr 122, 1792-1801.

47. Bingham SA, Gill C, Welch A et al. (1997) Validation of dietary assessment methods in the UK arm of EPIC using weighed records, and 24-hour urinary nitrogen and potassium and serum vitamin $\mathrm{C}$ and carotenoids as biomarkers. Int J Epidemiol 26, Suppl. 1, S137-S150.

48. Ocke MC \& Kaaks RJ (1997) Biochemical markers as additional measurements in dietary validity studies: application of the method of triads with examples from the European Prospective Investigation into Cancer and Nutrition. Am J Clin Nutr 65, 4 Suppl., 1240S-1245S.

49. Resnicow K, Odom E, Wang T et al. (2000) Validation of three food frequency questionnaires and 24-hour recalls with serum carotenoid levels in a sample of AfricanAmerican adults. Am J Epidemiol 152, 1072-1080.

50. Kobayashi M, Sasaki S \& Tsugane S (2003) Validity of a selfadministered food frequency questionnaire used in the 5-year follow-up survey of the JPHC Study Cohort I to assess carotenoids and vitamin $\mathrm{C}$ intake: comparison with dietary records and blood level. J Epidemiol 13, 1 Suppl., S82-S91.

51. Dixon LB, Subar AF, Wideroff L et al. (2006) Carotenoid and tocopherol estimates from the NCI Diet History Questionnaire are valid compared with multiple recalls and serum biomarkers. J Nutr 136, 3054-3061.

52. Dehghan M, Akhtar-Danesh N, McMillan CR et al. (2007) Is plasma vitamin $\mathrm{C}$ an appropriate biomarker of vitamin $\mathrm{C}$ intake? A systematic review and meta-analysis. Nutr J 6, 41.

53. Bingham SA, Welch AA, McTaggart A et al. (2001) Nutritional methods in the European prospective investigation of cancer in Norfolk. Public Health Nutr 4, 847-858.

54. Bodner CH, Soutar A, New SA et al. (1998) Validation of a food frequency questionnaire for use in a Scottish population: correlation of antioxidant vitamin intakes with biochemical measures. J Hum Nutr Diet 11, 373-380.

55. Knutsen SØF, Fraser GE, Linsted KD et al. (2001) Comparing biological measurements of vitamin $\mathrm{C}$, folate, $\alpha$-tocopherol and carotene with 24-hour dietary recall information in nonhispanic blacks and whites. Ann Epidemiol 11, 406-416.

56. Bolton-Smith C, Casey CE, Gey KF et al. (1991) Antioxidant vitamin intakes assessed using a food-frequency questionnaire: correlation with biochemical status in smokers and non-smokers. Br J Nutr 65, 337-346.

57. Jacques PF, Sulsky SI, Sadowski JA et al. (1993) Comparison of micronutrient intake measured by a dietary questionnaire and biochemical indicators of micronutrient status. Am J Clin Nutr 57, 182-189.

58. Kardinaal AFM, Van't Veer P, Brants HAM et al. (1995) Relations between antioxidant vitamins in adipose tissue, plasma, and diet. Am J Epidemiol 141, 440-450.

59. Porrini M, Gentile MG \& Fidanza F (1995) Biochemical validation of a self-administered semi-quantitative foodfrequency questionnaire. Br J Nutr 74, 323-333.

60. Boeing H, Bohlscheid-Thomas S, Voss S et al. (1997) The relative validity of vitamin intakes derived from a food frequency questionnaire compared to 24-hour recalls and biological measurements: results from the EPIC pilot study in Germany. European Prospective Investigation into Cancer and Nutrition. Int J Epidemiol 26, Suppl 1, S82-S90.

61. Marshall JR, Lanza E, Bloch A et al. (1997) Indexes of food and nutrient intakes as predictors of serum concentrations of nutrients: the problem of inadequate discriminant validity. The Polyp Prevention Trial Study Group. Am J Clin Nutr 65, 4 Suppl., 1269S-1274S.

62. Fraser GE, Butler TL \& Shavlik D (2005) Correlations between estimated and true dietary intakes: using two instrumental variables. Ann Epidemiol 15, 509-518. 
63. Willett WC, Stampfer MJ, Underwood BA et al. (1983) Validation of a dietary questionnaire with plasma carotenoid and $\alpha$-tocopherol levels. Am J Clin Nutr 38, 631-639.

64. Coates RJ \& Monteilh CP (1997) Assessments of foodfrequency questionnaires in minority populations. $\mathrm{Am} \mathrm{J}$ Clin Nutr 65, 4 Suppl., 1108S-1115S.

65. Shai I, Rosner BA, Shahar DR et al. (2005) Dietary evaluation and attenuation of relative risk: multiple comparisons between blood and urinary biomarkers, food frequency, and 24-hour recall questionnaires: the DEARR Study. J Nutr 135, 573-579.

66. Andersen LF, Solvoll K, Johansson LRK et al. (1999) Evaluation of a food frequency questionnaire with weighed records, fatty acids, and $\alpha$-tocopherol in adipose tissue and serum. Am J Epidemiol 150, 75-87.

67. El-Sohemy A, Baylin A, Ascherio A et al. (2001) Populationbased study of $\alpha$ - and $\gamma$-tocopherol in plasma and adipose tissue as biomarkers of intake in Costa Rican adults. Am J Clin Nutr 74, 356-363.

68. Jenab M, Slimani N, Bictash M et al. (2009) Biomarkers in nutritional epidemiology: applications, needs and new horizons. Hum Genet 125, 507-525.

69. Kaaks RJ (1997) Biochemical markers as additional measurements in studies of the accuracy of dietary questionnaire measurements: conceptual issues. Am J Clin Nutr 65, 4 Suppl., 1232S-1239S.

70. Zhang CX \& Ho SC (2009) Validity and reproducibility of a food frequency questionnaire among Chinese women in Guangdong province. Asia Pac J Clin Nutr 18, 240-250.

71. Lassale C, Guilbert C, Keogh J et al. (2009) Estimating food intakes in Australia: validation of the Commonwealth Scientific and Industrial Research Organisation (CSIRO) food frequency questionnaire against weighed dietary intakes. J Hum Nutr Diet 22, 559-566.

72. Bautista LE, Herrán OF \& Pryer JA (2005) Development and simulated validation of a food-frequency questionnaire for the Colombian population. Public Health Nutr 8, 181-188.

73. Ambrosini GL, De Klerk NH, Musk AW et al. (2001) Agreement between a brief food frequency questionnaire and diet records using two statistical methods. Public Health Nutr 4, 255-264.

74. Ambrosini GL, Mackerras D, De Klerk NH et al. (2003) Comparison of an Australian food-frequency questionnaire with diet records: implications for nutrition surveillance. Public Health Nutr 6, 415-422.

75. Statistics New Zealand (2007) 2006 Census Data: QuickStats about New Zealand's Population and Dwellings. Wellington: Statistics New Zealand.

76. Ministry of Health (2012) A Focus on Pacific Nutrition: Findings from the 2008/09 New Zealand Adult Nutrition Survey. Wellington: Ministry of Health.

77. Ministry of Health (2012) A Focus on Mãori Nutrition: Findings from the 2008/09 New Zealand Adult Nutrition Survey. Wellington: Ministry of Health. 